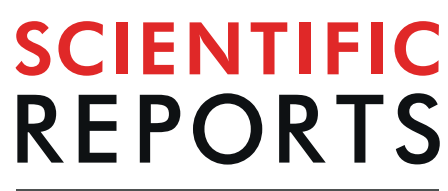

natureresearch

\title{
OPEN Associations between Coffee Products and Breast Cancer Risk: a Case-Control study in Hong Kong Chinese Women
}

Received: 26 March 2019

Accepted: 20 August 2019

Published online: 03 September 2019
Priscilla Ming Yi Lee ${ }^{1}$, Wing Cheong Chan ${ }^{2}$, Carol Chi-hei Kwok ${ }^{3}$, Cherry $\mathrm{Wu}^{4}$, Szehong Law ${ }^{5}$, Koon-ho Tsang ${ }^{6}$, Wai-cho Yu ${ }^{7}$, Yiu-cheong Yeung ${ }^{7}$, Lydia Dai Jia Chang ${ }^{8}$, Carmen Ka Man Wong ${ }^{1}$, Feng Wang ${ }^{1} \&$ Lap Ah Tse $^{1}$

Coffee contains caffeine and diterpenes that were associated with decreased breast cancer risk, but results remained inconsistent. The study purpose was to investigate the associations between coffee products and breast cancer risk among Hong Kong Chinese women. We conducted a hospitalbased case-control study in three public hospitals. 2169 Chinese women aged 24-84 years old were interviewed using a standardized questionnaire with questions asking types, cups and duration on coffee drinking. We used unconditional multivariate logistic regression to calculate the adjusted odds ratio $(A O R)$ and $95 \%$ confidence interval $(95 \% \mathrm{Cl})$ for breast cancer risk with different coffee products. $238(20.6 \%)$ cases and $179(17.7 \%)$ controls are habitual coffee drinkers. No association was found between overall coffee drinking and breast cancer risk. Compared to the non-habitual coffee drinkers, women who consumed instant coffee $(A O R=1.50,95 \% \mathrm{Cl}=1.10-2.03)$ were significantly associated with an increased breast cancer risk. Women who drank brewed coffee (AOR $=0.48,95 \% \mathrm{Cl}=0.28-0.82$ ) were negatively associated with breast cancer risk. A positive association between instant coffee and breast cancer risk was observed, contradicted to the outcomes of drinking brewed coffee. Larger studies are warranted to ascertain the role of different types of coffee products in breast cancer risk.

Globally, breast cancer is the most common cancer in women, and their dietary habits are among the most important factors contributing to the etiology of breast cancer ${ }^{1}$. In Hong Kong, coffee consumption is becoming more popular among local Chinese people. Statistics from Hong Kong Statista showed that the revenue of the coffee market increased by more than twice from 119 million USD in 2010 to 279 million USD in 2018, especially for that of the instant coffee ${ }^{2}$. Coffee consumption was classified as "possibly carcinogenic to humans" in 1991 but it has now been downgraded to "not classifiable as to carcinogenicity" in 1996 by the World Health Organization's International Agency for Research on Cancer ${ }^{3}$. The association between coffee consumption and the risk of developing breast cancer has been investigated since the 1970s, but the evidence from epidemiological studies remains controversial $^{4-9}$. Additionally, the composition of coffee is different among a variety of coffee products, such as instant coffee and brewed coffee, so these products may contribute differently to breast cancer risk.

A recent meta-analysis of 13 prospective studies did not show any significant association between coffee consumption and the risk of breast cancer, but an inverse relationship was found among postmenopausal women (relative risk $=0.90,95 \%$ confidence interval $(95 \% \mathrm{CI}): 0.82-0.99)^{10}$. A prospective cohort study with 22 years of follow-up in Boston also demonstrated an inverse association of caffeine consumption, and the association

${ }^{1}$ The Jockey Club School of Public Health and Primary Care, Faculty of Medicine, The Chinese University of Hong Kong, Hong Kong, People's Republic of China. ${ }^{2}$ Department of Surgery, North District Hospital, Hong Kong, People's Republic of China. ${ }^{3}$ Department of Oncology, Princess Margaret Hospital, Hong Kong, People's Republic of China. ${ }^{4}$ Department of Pathology, North District Hospital, Hong Kong, People's Republic of China. ${ }^{5}$ Department of Surgery, Yan Chai Hospital, Hong Kong, People's Republic of China. ${ }^{6}$ Department of Pathology, Yan Chai Hospital, Hong Kong, People's Republic of China. 'Department of Medicine, Princess Margaret Hospital, Hong Kong, People's Republic of China. ${ }^{8}$ Department of Biological Sciences, University of Toronto Scarborough, Toronto, Canada. Priscilla Ming Yi Lee and Wing Cheong Chan contributed equally. Correspondence and requests for materials should be addressed to L.A.T. (email: shelly@cuhk.edu.hk) 
was stronger with estrogen-receptor positive and progesterone-receptor positive breast cancer than that with the estrogen-receptor negative and progesterone-receptor negative breast cancer ${ }^{4}$. This inverse association may be caused by different coffee compounds and chemicals including caffeine, diterpene and polyphenols, which may influence breast cancer mechanisms. Coffee is the major dietary source of caffeine, and previous in vitro studies suggested that caffeine may bind the estrogen hormones through increased levels of sex hormone-binding globulin among post-menopausal women ${ }^{11}$. Thus, caffeine consumption may lower the levels of circulating sex hormones, thereby reduces the risk of breast cancer.

Different coffee products may also contain various levels of sugars and food additives, which may affect the rising trend of breast cancer in different ways. A majority of coffee consumption in Hong Kong is from instant coffee, while brewed coffee is the most popular choice in Western countries ${ }^{2}$. The toxicity of instant coffee in the Hong Kong market was tested by the Vitargent (International) Biotechnology Limited who followed the international standards (the CODEX Alimentarius of the WHO\&FAO, European Union, and Food and Drug Administration of the United State and Japan $)^{12}$. They found that more than $30 \%$ of instant coffee samples failed to achieve the standard in one or more of the following criteria regarding the acute toxicity, chronic toxicity and banned ingredients of instant coffee products (e.g., the chemicals disrupted the estrogenic endocrine system $)^{12}$. However, there currently remains a lack of knowledge on the relationship between different coffee products and breast cancer risk in women. It is also important to note that the differences in coffee habits between Asian and Western countries. The highest level of coffee consumption in most of the studies conducted in Western countries was $\geq 4$ cups per day, whereas the highest level in Asian countries was only $\geq 1$ cup(s) per day ${ }^{2}$, thus the coffee consumption in Western countries and its contribution to breast cancer are not applicable to the Hong Kong population. To address this information, this study aims to investigate the associations between different coffee products (mainly focusing on instant coffee and brewed coffee) and breast cancer risk among Hong Kong Chinese women.

\section{Results}

One thousand one hundred and fifty-six newly diagnosed breast cancer cases and 1,013 controls were recruited in this study with a response rate of $88.4 \%$ and $89.5 \%$, respectively. As shown in Table 1, breast cancer cases were older than controls, more likely to be overweight and had a family history of breast cancer. The pattern of educational attainment, previous history of benign breast diseases, menopausal status, shift work experience, tobacco smoking, alcohol consumption and tea consumption, and deep fried food and green vegetable consumption was similar between the cases and controls.

The distribution of specific coffee products and the associations with breast cancer is summarized in Table 2 . A total of 239 (20.7\%) cases and 179 (17.7\%) controls were habitual coffee drinkers. Among them, 161 (13.9\%) cases and 128 (12.6) controls consumed at least one cup of coffee per day. No association was observed between habitual coffee drinking or the number of cups of coffee consumption with breast cancer risk. However, subgroup analysis by different coffee products showed that breast cancer risk was negatively associated with habitual brewed coffee consumption $(\mathrm{AOR}=0.48,95 \% \mathrm{CI}=0.28-0.82$ ) (Table 2$)$, showing an exposure-response relationship with increasing cups of brewed coffee ( $\mathrm{p}$ for trend $<0.01$ ). Women who drank coffee served in restaurants at least once a week showed an even lower $\mathrm{OR}$ of the risk of breast cancer $(\mathrm{AOR}=0.23,95 \% \mathrm{CI}=0.08-0.65$, $\mathrm{p}$ for trend $<0.01)$ (Table 3). In contrast, women who habitually drank instant coffee had an $41 \%$ increased risk of breast cancer (Table 2), showing a positive gradient of breast cancer risk with increasing consumption of instant coffee ( $p$ for trend $=0.02$ ). The risk of breast cancer increased 1.51 fold among the habitual consumption of two-in-one or three-in-one instant coffee (Table 3). Furthermore, compared with women who habitually drank brewed coffee, women who drank instant coffee have an increased odds of breast cancer $(\mathrm{AOR}=2.77,95 \% \mathrm{CI}=1.49-5.13)$ after adjustment of same confounding factors as those are listed in Table 2 (Table 4).

Results of multivariate logistic regressions for the duration of specific coffee products are presented in Table 5. Consistent with the findings of overall coffee consumption, the duration of consumption of coffee overall was not associated with the risk of breast cancer $(\mathrm{AOR}=1.10,95 \% \mathrm{CI}=0.80-1.53)$. However, women who drank instant coffee for more than ten years had an $48 \%$ increased risk of breast cancer. This was conflicting to that of in women who drank brewed coffee ( $\mathrm{AOR}=0.40,95 \% \mathrm{CI} 0.21-0.77)$.

Sensitivity analyses were conducted by further including history of hypertension and diabetes mellitus into the multivariate logistic models. As shown in Supplement I-III, the AORs for breast cancer were similar to those obtained from the models without including history of hypertension and diabetes. For instance, the AOR for instant coffee in the model without history of hypertension and diabetes vs. the model with history of hypertension and diabetes was $1.50(1.10-2.03)$ vs. 1.52 (95\% CI: 1.11-2.07), while the corresponding AOR for brewed coffee was $0.48(0.28-0.82)$ vs. 0.52 (95\% CI: $0.30-0.90)$, respectively.

We performed further stratified analyses according to menopausal status (Table 6). Among postmenopausal women, the association for instant coffee, brewed coffee and restaurant coffee retained statistical significance. However, a significantly positive association with the pre-menopausal breast cancer was only observed among those who had habits of drinking two-in-one or three-in-one coffee $(\mathrm{AOR}=5.37,95 \% \mathrm{CI}=1.14-25.38)$.

\section{Discussion}

This hospital-based case-control study demonstrated the different associations between brewed coffee and instant coffee with breast cancer risk. Women who habitually consumed brewed coffee were associated with $52 \%$ lower in the risk of breast cancer, and the inverse association was even predominant among postmenopausal women. In contrast, instant coffee consumption was positively associated with the risk of breast cancer, and a further higher risk was observed among habitual two-in-one or three-in-one coffee drinkers who were pre-menopausal. These findings add additional evidence to the current literature on the association between coffee products and the risk of breast cancer. 


\begin{tabular}{|c|c|c|c|}
\hline Characteristic & $\begin{array}{l}\text { Controls } \\
(N=1013)\end{array}$ & $\begin{array}{l}\text { Cases }(N=1 \\
156)\end{array}$ & $p$-value \\
\hline Age, Mean \pm SD & $54.25 \pm 11.7$ & $56.53 \pm 11.8$ & $<0.01$ \\
\hline \multicolumn{4}{|c|}{ Educational attainment, $\mathrm{n}(\%)$} \\
\hline Primary or below & $364(35.9)$ & $429(37.1)$ & \\
\hline Secondary & $529(52.2)$ & $579(50.1)$ & \\
\hline Tertiary & $77(7.6)$ & $78(6.7)$ & \\
\hline Unknown & $43(4.2)$ & $70(6.1)$ & 0.59 \\
\hline \multicolumn{4}{|c|}{ Family breast cancer history, $\mathrm{n}(\%)$} \\
\hline No & $972(96.0)$ & $1031(89.2)$ & \\
\hline Yes & $41(4.0)$ & $125(10.8)$ & $<0.01$ \\
\hline \multicolumn{4}{|c|}{ Previous history of benign breast diseases, $\mathrm{n}(\%)$} \\
\hline No & $913(90.1)$ & $1017(88.0)$ & \\
\hline Yes & $100(9.9)$ & $139(12.0)$ & 0.11 \\
\hline \multicolumn{4}{|l|}{ Menopausal status } \\
\hline Pre-menopausal & $341(33.7)$ & $388(33.6)$ & \\
\hline Post-menopausal & $616(60.8)$ & $695(60.1)$ & \\
\hline Unknown & $56(5.5)$ & $73(6.3)$ & 0.93 \\
\hline \multicolumn{4}{|l|}{ Body mass index, $\mathrm{n}(\%)$} \\
\hline Normal (18.5-24.9) & $541(53.4)$ & $630(54.5)$ & \\
\hline Underweight $(<18.5)$ & $83(8.7)$ & $56(4.8)$ & \\
\hline Overweight $(\geq 25.0)$ & $228(22.5)$ & $399(34.5)$ & \\
\hline Unknown & $161(15.9)$ & $71(6.1)$ & $<0.01$ \\
\hline \multicolumn{4}{|l|}{ Shift work, n (\%) } \\
\hline No & $861(85.0)$ & $1007(87.1)$ & \\
\hline Yes & $152(15.0)$ & $149(12.9)$ & 0.16 \\
\hline \multicolumn{4}{|l|}{ Tobacco smoking, n (\%) } \\
\hline Never & $933(92.1)$ & $1077(93.2)$ & \\
\hline Former & $34(3.4)$ & $37(3.2)$ & \\
\hline Current & $46(4.5)$ & $42(3.6)$ & 0.55 \\
\hline \multicolumn{4}{|c|}{ Alcohol consumption, n (\%) } \\
\hline Non users & $969(95.7)$ & $1098(95.0)$ & \\
\hline Users & $44(4.3)$ & $58(5.0)$ & 0.46 \\
\hline \multicolumn{4}{|l|}{ Tea consumption, $\mathrm{n}(\%)$} \\
\hline Non users & $434(42.8)$ & $467(40.4)$ & \\
\hline Users & $579(57.2)$ & $689(59.6)$ & 0.25 \\
\hline \multicolumn{4}{|c|}{ Deep Fried food consumption, n (\%) } \\
\hline $\begin{array}{l}\text { Less than once per } \\
\text { month }\end{array}$ & $453(44.7)$ & $518(44.8)$ & \\
\hline Once per month & $381(37.6)$ & $429(37.1)$ & \\
\hline Once per week & $177(17.5)$ & $208(18.0)$ & 0.94 \\
\hline \multicolumn{4}{|c|}{ Green vegetable consumption, $\mathrm{n}(\%)$} \\
\hline $\begin{array}{l}\text { Less than } 3 \text { times per } \\
\text { week }\end{array}$ & $110(10.9)$ & $128(11.1)$ & \\
\hline 4-6 times per week & $90(8.9)$ & $128(11.1)$ & \\
\hline Everyday & $813(80.3)$ & $900(77.9)$ & 0.22 \\
\hline
\end{tabular}

Table 1. Distribution of selected characteristics of 1156 cases and 1013 controls among Hong Kong women.

We found that the duration and number of cups of brewed coffee consumption were negatively associated with the risk of breast cancer among Hong Kong Chinese women. Women who drank more than one cup of brewed coffee per day and drank for more than ten years were inversely associated with $60 \%$ breast cancer risk, respectively. One possible mechanism of this association may be related to the rich polyphenols (such as, caffeic acid and chlorogenic acid) in coffee, which may inhibit the breast cancer related gene RAR-Beta's promoter and methylation ${ }^{13}$. Another mechanism of this negative association between brewed coffee and breast cancer risk may be related to a high level of caffeine intake which was evidently to be associated with a lower level of circulating estrogen $^{11,14}$. A high level of circulating estrogen was found to be associated with a significantly increased risk of breast cancer ${ }^{15}$. Caffeine consumption may reduce total luteal cells and free estradiol level in premenopausal women ${ }^{14}$ but increase the levels of sex hormone-binding globulin in postmenopausal women ${ }^{11}$. In postmenopausal women, the ovaries were not the major source of estrogen, as the estradiol may be produced in a number of extragonadal sites $^{16}$. Sex hormone-binding globulin helps to bind the estradiol and testosterone from number of extragonadal 


\begin{tabular}{|c|c|c|c|c|}
\hline Variables & $\begin{array}{l}\text { Controls } \\
(N=1013)\end{array}$ & $\begin{array}{l}\text { Cases }(N=1 \\
156)\end{array}$ & $\begin{array}{l}\text { Crude OR (95\% } \\
\text { CI) }\end{array}$ & $\begin{array}{l}\text { Adjusted OR (95\% } \\
\text { CI) }\end{array}$ \\
\hline Coffee drinking, $\mathrm{n}(\%)$ & $179(17.7)$ & $238(20.6)$ & $1.21(0.97-1.50)$ & $1.14(0.88-1.47)$ \\
\hline Instant coffee & $113(11.2)$ & $182(15.7)$ & $1.52(1.18-1.99)$ & $1.50(1.10-2.03)$ \\
\hline Two/Three in one & $15(1.5)$ & $37(3.2)$ & $2.24(1.22-4.11)$ & $2.52(1.24-5.13)$ \\
\hline Brewed coffee & $59(5.8)$ & $43(3.7)$ & $0.57(0.36-0.90)$ & $0.48(0.28-0.82)$ \\
\hline Homemade coffee & $25(2.5)$ & $26(2.2)$ & $0.86(0.45-1.65)$ & $0.67(0.31-1.43)$ \\
\hline Restaurant coffee & $36(3.6)$ & $17(1.5)$ & $0.39(0.20-0.76)$ & $0.33(0.16-0.69)$ \\
\hline Others $^{\mathrm{e}}$ & $19(1.9)$ & $26(2.2)$ & $1.24(0.68-2.26)$ & $1.17(0.60-2.28)$ \\
\hline
\end{tabular}

Table 2. Distribution of specific coffee product among coffee consumption and its association with breast cancer risk ${ }^{\mathrm{a}}$. ${ }^{\mathrm{a}}$ Participants with missing values were excluded from the analysis. ${ }^{\mathrm{b}}$ The reference group was defined as the participants who did not have a habitual coffee consumption (i.e., coffee drinking vs. non-coffee drinking; instant coffee drinking vs. non- coffee drinking). ${ }^{c}$ Participants who drank both instant coffee and brewed coffee were excluded in the logistic regression models. ${ }^{\mathrm{d}}$ Adjusted for age at interview, educational attainment, family breast cancer history, previous history of benign breast diseases, body mass index (BMI), shift work experiences, smoking status, alcohol and tea drinking consumption, and deep fried food and green vegetable consumption. ${ }^{e}$ Other coffee referred to those who drank decaffeinated coffee or had no preferable coffee products.

sites which decreases the levels of bioavailable estradiol and testosterone ${ }^{11}$, and the levels of sex hormone-binding globulin were associated with decreased risk of breast cancer among postmenopausal women ${ }^{17}$. Previous epidemiological study also observed an association of caffeine with higher levels of sex hormone-binding globulin and low levels of free testosterone ${ }^{14}$, which explains an inverse association between coffee intake and breast cancer risk through the possible pathway of estrogen among postmenopausal ${ }^{11}$. By contrast, the principal source of estrogen is produced in ovaries among premenopausal women whose estrogen levels are relatively higher than the postmenopausal women ${ }^{16}$, which explains the reduction of estrogen levels induced by the intake of coffee may not affect much on the risk of breast cancer for the premenopausal women. As a result, brewed coffee consumption may decrease the risk of breast cancer via reducing the levels of estrogen among postmenopausal women but not significant in premenopausal women. Consistent with some of the previous studies ${ }^{4,5,10}$, our study also demonstrated a significantly negative association between brewed coffee consumption habits and breast cancer risk in the postmenopausal women. However, one recent meta-analysis study reported a similarly pooled negative association of caffeinated and decaffeinated coffee with breast cancer risk ${ }^{5}$. These negative associations from the meta-analysis may suggest other potential coffee protective substances in coffee or the potential protective effects, which only affects post-menopausal women.

Another putative mechanism for the inverse association of brewed coffee consumption and breast cancer risk was the exposure of diterpene. The levels of diterpene vary among different brewing methods ${ }^{18}$. Higher levels of two specific coffee diterpenes, cafestol and kahweol are more evident in boiled coffee than in filtered coffee ${ }^{18}$. These two diterpenes produced the biochemical effects such as induction of conjugating enzymes and increased protein expression in cellular antioxidant defense, which may result in a reduction of the genotoxicity of several carcinogens, such as 7,12-Dimethylbenz(a)anthracene, benzopyrene and 2-amino-1-methyl-6-phenylimidazo(4, 5 -b)pyridine ${ }^{19,20}$. The anti-carcinogenic activity of cafestrol and kahweol reduces the expression and inhibits enzymatic activity of phase I enzyme for carcinogen activation, and induces phase II enzymes in carcinogen detoxification ${ }^{19}$. Kahweol increased the production of reactive oxygen species and their cytotoxicity in breast cancer cells, which enhances apoptosis of breast tumor cells ${ }^{20}$. One prospective cohort study conducted in Vasterbotten reports a significantly decreased risk of breast cancer among women who habitually drink boiled coffee, but a weaker positive association was suggested in women with habitual filtered coffee drinking ${ }^{7}$. Among our participants who have habitual restaurant coffee drinking habits, approximately $90 \%$ of them drank their coffee in Hong Kong-style diners (cha chaan teng) or Hong Kong-style fast food restaurants. Such restaurants serve boiled coffee, which may be a plausible explanation of the stronger association with breast cancer observed in restaurant coffee than that of the homemade coffee.

Intriguingly, there is a positive association of instant coffee consumption with the risk of breast cancer, and a clear exposure- response relationship of cups of instant coffee was revealed with breast cancer risk. These instant coffees contain less coffee but more additives, such as non-diary creamer, sugar and stabilizers to maintain the coffee texture, taste and smell. However, these additives may also contain hydrogenated fats and/or trans-saturated fats that may increase breast cancer risk ${ }^{21}$. In addition, habitual instant coffee drinkers tend to have lower serum levels of high density lipoprotein (HDL) cholesterol ${ }^{22}$. One population-based study in Troms reported that low serum HDL cholesterol was associated with increased levels of estradiol concentration ${ }^{23}$, which may further increase the risk of breast cancer among the instant coffee drinkers.

To the best of our knowledge, this is the first study reporting the association between different coffee products (i.e. instant coffee and brewed coffee) and breast cancer risk in Hong Kong Chinese women. Information on coffee consumption habits were amassed, such as the type of coffee products, the number of cups and years consumed. Results of our study propose that instant coffee may be a novel breast cancer risk factor. We recruited our participants from three large public hospitals, covering around $8.5 \%$ of those who had breast cancer in Hong Kong's population, with a high response rate (88.4\%). We further re-interviewed 158 cases and 153 controls at least one month after the initial recruitment and showed good overall test-retest reliability for tea drinking (Kappa 


\begin{tabular}{|c|c|c|c|c|}
\hline Cups of coffee drinking per day, n (\%) & $\begin{array}{l}\text { Controls } \\
(N=1013)\end{array}$ & $\begin{array}{l}\text { Cases } \\
(N=1156)\end{array}$ & Crude OR $(95 \% \mathrm{CI})^{\mathrm{bc}}$ & Adjusted OR $(95 \% \mathrm{CI})^{\mathrm{bcd}}$ \\
\hline \multicolumn{5}{|l|}{ Overall coffee } \\
\hline Non-habitual coffee drinker & $834(82.3)$ & $918(79.4)$ & 1.00 & 1.00 \\
\hline$<1$ cup/day & $51(5.0)$ & $77(6.7)$ & $1.37(0.95-1.98)$ & $1.22(0.80-1.85)$ \\
\hline$\geq 1$ cup/day & $128(12.6)$ & $161(13.9)$ & $1.14(0.89-1.47)$ & $1.09(0.81-1.46)$ \\
\hline \multicolumn{5}{|l|}{ Instant coffee } \\
\hline Non-habitual coffee drinker & $900(88.8)$ & $974(84.3)$ & 1.00 & 1.00 \\
\hline$<1$ cup/day & $37(3.7)$ & $63(5.4)$ & $1.55(1.02-2.35)$ & $1.36(0.85-2.17)$ \\
\hline$\geq 1$ cup/day & $76(7.5)$ & $119(10.3)$ & $1.42(1.05-1.93)$ & $1.45(1.02-2.06)$ \\
\hline \multicolumn{5}{|l|}{ Two/Three in one } \\
\hline Non-habitual coffee drinker & $998(98.5)$ & $1119(96.8)$ & 1.00 & 1.00 \\
\hline$<1$ cup/day & $4(0.4)$ & $10(0.9)$ & $2.27(0.71-7.27)$ & $2.91(0.61-13.91)$ \\
\hline$\geq 1$ cup/day & $11(1.1)$ & $27(2.3)$ & $2.23(1.10-4.52)$ & $2.51(1.14-5.57)$ \\
\hline \multicolumn{5}{|l|}{ Brewed coffee } \\
\hline Non-habitual coffee drinker & $954(94.2)$ & $1112(96.3)$ & 1.00 & 1.00 \\
\hline$<1$ cup/day & $24(2.4)$ & $25(2.2)$ & $0.95(0.54-1.67)$ & $0.67(0.35-1.29)$ \\
\hline$\geq 1$ cup/day & $35(3.5)$ & $18(1.6)$ & $0.47(0.26-0.83)$ & $0.40(0.20-0.76)$ \\
\hline \multicolumn{5}{|l|}{ Homemade coffee } \\
\hline Non-habitual coffee drinker & $889(97.7)$ & $902(97.5)$ & 1.00 & 1.00 \\
\hline$<1$ cup/day & $10(1.0)$ & $13(1.1)$ & $1.18(0.52-2.71)$ & $0.93(0.37-2.33)$ \\
\hline$\geq 1$ cup/day & $15(1.5)$ & $13(1.1)$ & $0.79(0.37-1.66)$ & $0.65(0.27-1.60)$ \\
\hline \multicolumn{5}{|l|}{ Restaurant coffee } \\
\hline Non-habitual coffee drinker & $977(96.4)$ & $1139(98.5)$ & 1.00 & 1.00 \\
\hline$<1$ cup/day & $17(1.7)$ & $12(1.0)$ & $0.64(0.30-1.35)$ & $0.44(0.19-1.03)$ \\
\hline$\geq 1$ cup/day & $19(1.9)$ & $5(0.4)$ & $0.24(0.09-0.64)$ & $0.23(0.08-0.65)$ \\
\hline \multicolumn{5}{|l|}{ Others $^{\mathrm{e}}$} \\
\hline Non-habitual coffee drinker & $897(98.2)$ & 898 (97.4) & 1.00 & 1.00 \\
\hline$<1$ cup/day & $6(0.6)$ & $12(1.0)$ & $1.82(0.68-4.86)$ & $2.30(0.69-7.64)$ \\
\hline$\geq 1 \mathrm{cup} /$ day & $13(1.3)$ & $14(1.2)$ & $0.98(0.46-2.09)$ & $0.80(0.35-1.80)$ \\
\hline
\end{tabular}

Table 3. Distribution of number of cups of coffee products and its association with breast cancer risk ${ }^{\mathrm{a}}$.

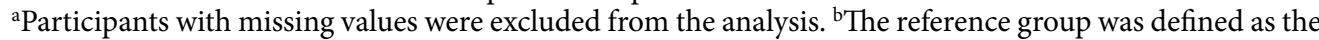
participants who did not have a habitual coffee consumption (i.e., coffee drinking vs. non-coffee drinking; instant coffee drinking vs. non- coffee drinking). ${ }^{c}$ Participants who drank both instant coffee and brewed coffee were excluded in the logistic regression models. ${ }^{\mathrm{d}}$ Adjusted for age at interview, educational attainment, family breast cancer history, previous history of benign breast diseases, body mass index (BMI), shift work experiences, smoking status, alcohol and tea drinking consumption, and deep fried food and green vegetable consumption. ${ }^{\text {e}}$ Other coffee referred to those who drank decaffeinated coffee or had no preferable coffee products.

consistency rate of 83\%). However, the major limitations of our study do exist. We did not collect the information regarding the preparation method of coffee (e.g., filtered, boiled), in which the content of compounds and chemicals including caffeine may vary. Misclassification of the concentration of caffeine and other components in the different coffee product may also be a concern, as we do not have direct measurements of each content. Furthermore, the issue of chance cannot be entirely excluded in subgroup analysis for the associations between different coffee products and breast cancer, since the 95\% CI was relatively broad. Despite the mechanism for instant coffee on the risk of breast cancer is not yet clear and the significant results of these associations could be due by chance, the consistently positive dose-response relationships between daily amount of consumption or duration of instant coffee drinking with breast cancer risk increase the plausibility of our findings. Generally, the concern of the recall and/or interviewer bias cannot be eliminated in case-control studies, and thus we used a standardized approach to interview all participants and interviewed the controls within 6 month after the cases were recruited, which in turn reduced the potential recall and interview bias. In addition, we compared the findings between cases recruited from Department of Survey (cases were interviewed before biopsy) with those from Department of Clinical Oncology (the diagnosis of breast cancer had been known), and they were similar which further supports that the potential recall and/or interveiw bias of our study should not be a main concern. Selection bias of breast cases may be a concern as all cases of our study came from three hospitals. We found a similar proportion of incident breast cancer in different age groups to those obtained from the Hong Kong Cancer Registry from 2011 to 2016 (i.e. the last updated year) ${ }^{24}$, indicating a good comparability between our cases and the general population. Controls recruited from the hospitals may not well represent the general population; however, we recruited controls with a variety of disease types from the same hospitals that were not related to any type of breast diseases. Previous hospital-based case-control studies provide evidence that a similar magnitude of risk was obtained between using the general population controls and hospital controls with a variety of disease types $^{25}$. Thus, the potential selection bias, if presents in this study, should not be a major issue. 


\begin{tabular}{|l|l|l|l|l|}
\hline Variables & $\begin{array}{l}\text { Controls } \\
(\mathbf{N = 1 0 1 3})\end{array}$ & $\begin{array}{l}\text { Cases } \\
(\mathbf{N = 1 1 5 6 )}\end{array}$ & Crude OR $(\mathbf{9 5} \% \mathbf{C I})^{\mathbf{b c}}$ & ${\text { Adjusted OR }(\mathbf{9 5} \% \mathbf{C I})^{\mathrm{cd}}}^{\mathrm{c}}$ \\
\hline Brewed coffee & $59(5.8)$ & $26(2.2)$ & $1.00^{\mathrm{a}}$ & $1.00^{\mathrm{a}}$ \\
\hline Instant coffee & $113(11.2)$ & $182(15.7)$ & $\mathbf{2 . 5 5}(\mathbf{1 . 5 2 - 4 . 2 8})$ & $\mathbf{2 . 7 7 ( 1 . 4 9 - 5 . 1 3 )}$ \\
\hline
\end{tabular}

Table 4. Associations between controls and breast cancers in brewed coffee and instant coffee consumption. ${ }^{a}$ The reference group was defined as the participants who have habitual brewed coffee consumption. ${ }^{\mathrm{b}}$ Using brewed coffee as reference group and no other variables were adjusted in the model. 'Participants who drank both instant coffee and brewed coffee were excluded in the logistic regression models. ${ }^{\mathrm{d}}$ Adjusted for age at interview, educational attainment, family breast cancer history, previous history of benign breast diseases, body mass index (BMI), shift work experiences, smoking status, alcohol and tea drinking consumption, and deep fried food and green vegetable consumption.

\begin{tabular}{|c|c|c|c|c|}
\hline Duration of coffee consumption, $\mathbf{n}(\%)$ & $\begin{array}{l}\text { Controls } \\
(N=1013)\end{array}$ & $\begin{array}{l}\text { Cases } \\
(N=1156)\end{array}$ & Crude OR $(95 \% \text { CI })^{b c}$ & Adjusted OR $(95 \% \mathrm{CI})^{\mathrm{bcd}}$ \\
\hline \multicolumn{5}{|l|}{ Overall coffee } \\
\hline Non-habitual coffee drinker & $834(82.3)$ & $917(79.3)$ & 1.00 & 1.00 \\
\hline $5-10$ years & $81(8.0)$ & $107(9.3)$ & $1.20(0.89-1.63)$ & $1.15(0.81-1.63)$ \\
\hline$>10$ years & $98(9.7)$ & $131(11.3)$ & $1.21(0.92-1.60)$ & $1.10(0.80-1.53)$ \\
\hline \multicolumn{5}{|l|}{ Instant coffee } \\
\hline Non-habitual coffee drinker & $900(89.8)$ & $974(84.3)$ & 1.00 & 1.00 \\
\hline $5-10$ years & $52(5.1)$ & $83(7.2)$ & $1.48(1.03-2.11)$ & $1.45(0.97-2.17)$ \\
\hline$>10$ years & $61(6.0)$ & $99(8.6)$ & $1.50(1.08-2.09)$ & $1.48(1.01-2.17)$ \\
\hline \multicolumn{5}{|l|}{ Two/Three in one } \\
\hline Non-habitual coffee drinker & $998(98.5)$ & $1119(96.8)$ & 1.00 & 1.00 \\
\hline $5-10$ years & $6(0.6)$ & $15(1.3)$ & $2.27(0.89-5.88)$ & $2.99(0.94-9.42)$ \\
\hline$>10$ years & $9(0.9)$ & $22(1.9)$ & $2.22(1.02-4.85)$ & $2.23(0.92-5.43)$ \\
\hline \multicolumn{5}{|l|}{ Brewed coffee } \\
\hline Non-habitual coffee drinker & $954(94.2)$ & $1112(96.2)$ & 1.00 & 1.00 \\
\hline 5-10 years & $27(2.7)$ & $20(1.7)$ & $0.67(0.38-1.21)$ & $0.66(0.35-1.26)$ \\
\hline$>10$ years & $32(3.2)$ & $23(2.0)$ & $0.65(0.38-1.13)$ & $0.40(0.21-0.77)$ \\
\hline \multicolumn{5}{|l|}{ Homemade coffee } \\
\hline Non-habitual coffee drinker & $989(97.6)$ & $1130(97.8)$ & 1.00 & 1.00 \\
\hline $5-10$ years & $13(1.3)$ & $13(1.1)$ & $0.87(0.40-1.90)$ & $0.89(0.38-2.07)$ \\
\hline$>10$ years & $12(1.2)$ & $13(1.1)$ & $0.95(0.43-2.09)$ & $0.62(0.24-1.61)$ \\
\hline \multicolumn{5}{|l|}{ Restaurant coffee } \\
\hline Non-habitual coffee drinker & $976(96.3)$ & $1138(98.4)$ & 1.00 & 1.00 \\
\hline $5-10$ years & $15(1.5)$ & $7(0.6)$ & $0.40(0.16-0.99)$ & $0.44(0.17-1.11)$ \\
\hline$>10$ years & $21(2.1)$ & $10(0.9)$ & $0.41(0.19-0.87)$ & $0.26(0.11-0.64)$ \\
\hline \multicolumn{5}{|l|}{ Others $^{\mathrm{e}}$} \\
\hline Non-habitual coffee drinker & $994(98.1)$ & $1130(97.8)$ & 1.00 & 1.00 \\
\hline $5-10$ years & $8(0.8)$ & $11(1.0)$ & $1.21(0.49-3.02)$ & $1.04(0.35-3.10)$ \\
\hline$>10$ years & $11(1.1)$ & $15(1.3)$ & $1.20(0.55-2.62)$ & $1.18(0.51-2.71)$ \\
\hline
\end{tabular}

Table 5. Distribution of duration of specific coffee product and its association with breast cancer risk ${ }^{\mathrm{a}}$. aParticipants with missing values were excluded from the analysis. ${ }^{\mathrm{b}}$ The reference group was defined as the participants who did not have a habitual coffee consumption (i.e., coffee drinking vs. non-coffee drinking; instant coffee drinking vs. non- coffee drinking). 'Participants who drank both instant coffee and brewed coffee were excluded in the logistic regression models. ${ }^{\mathrm{d}}$ Adjusted for age at interview, educational attainment, family breast cancer history, previous history of benign breast diseases, body mass index (BMI), shift work experiences, smoking status, alcohol and tea drinking consumption, and deep fried food and green vegetable consumption. ${ }^{e}$ Other coffee referred to those who drank decaffeinated coffee or had no preferable coffee products.

In summary, this study revealed that breast cancer among Chinese women in Hong Kong was inversely associated with the consumption of brewed coffee but positively related to the intake of instant coffee. Nevertheless, it should be noted that breast cancer cases in this study showed a low prevalence of habitual coffee consumption. Future larger analytic studies with different population subsets and types of coffee products are warranted. 


\begin{tabular}{|c|c|c|c|c|c|c|}
\hline \multirow[b]{2}{*}{ Characteristics } & \multicolumn{3}{|c|}{ Pre-menopausal } & \multicolumn{3}{|c|}{ Post-menopausal } \\
\hline & $\begin{array}{l}\text { Control } \\
n=341\end{array}$ & $\begin{array}{l}\text { All cases } \\
n=388\end{array}$ & $\begin{array}{l}\text { Adjusted OR }{ }^{\text {bcd }} \\
(95 \% \text { CI })\end{array}$ & $\begin{array}{l}\text { Control } \\
n=616\end{array}$ & $\begin{array}{l}\text { All cases } \\
n=695\end{array}$ & $\begin{array}{l}\text { Adjusted } O^{\text {bcd }} \\
(95 \% \mathrm{CI})\end{array}$ \\
\hline Coffee drinking, n (\%) & $67(19.6)$ & $78(20.1)$ & $1.00(0.65-1.54)$ & $106(17.2)$ & $149(21.4)$ & $1.15(0.83-1.60)$ \\
\hline Instant coffee & $42(12.3)$ & $60(15.5)$ & $1.44(0.86-2.44)$ & $67(10.9)$ & $114(16.4)$ & $1.52(1.03-2.25)$ \\
\hline Two/Three in one & $3(0.9)$ & $13(3.4)$ & $5.37(1.14-25.38)$ & $12(1.9)$ & $23(3.3)$ & $1.82(0.79-4.17)$ \\
\hline Brewed coffee & $24(7.0)$ & $18(4.6)$ & $0.51(0.21-1.19)$ & $34(5.5)$ & $23(3.3)$ & $0.40(0.20-0.83)$ \\
\hline Homemade coffee & $9(2.6)$ & $6(1.5)$ & $0.61(0.13-2.91)$ & $15(2.4)$ & $19(2.7)$ & $0.75(0.31-1.84)$ \\
\hline Restaurant coffee & $15(4.4)$ & $11(2.8)$ & $0.48(0.17-1.30)$ & $21(3.4)$ & $4(0.6)$ & $0.13(0.04-0.49)$ \\
\hline Others ${ }^{\mathrm{e}}$ & $8(2.3)$ & $8(2.1)$ & $0.72(0.25-2.11)$ & $10(1.6)$ & $18(2.6)$ & $1.41(0.57-3.47)$ \\
\hline
\end{tabular}

Table 6. Association between controls and breast cancers in coffee products consumption stratified by

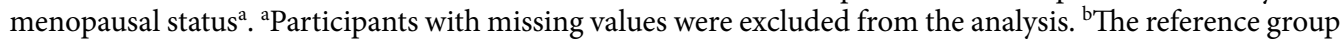
was defined as the participants who did not have a habitual coffee consumption (i.e., coffee drinking vs. noncoffee drinking; instant coffee drinking vs. non- coffee drinking). ${ }^{c}$ Participants who drank both instant coffee and brewed coffee were excluded in the logistic regression models. ${ }^{\mathrm{d}}$ Adjusted for age at interview, educational attainment, family breast cancer history, previous history of benign breast diseases, body mass index (BMI), shift work experiences, smoking status, alcohol and tea drinking consumption, and deep fried food and green vegetable consumption. ${ }^{e}$ Other coffee referred to those who drank decaffeinated coffee or had no preferable coffee products.

\section{Methods}

Study population and design. Details of the study design and subject characteristics have been described elsewhere ${ }^{26}$. We conducted a hospital-based case-control study in three Hong Kong public hospitals from November 2011 to January 2018. Trained interviewers conducted a face-to-face interviews with a standardized questionnaire and obtained a written informed consent form. Eligible cases were Chinese women aged 24-84 years-old who were newly diagnosed as having primary breast cancer (International Classification of Disease, Tenth Revision, code 50) within three months prior to the interview. We matched each case with one control by 5 -year age group who did not have any conditions pertaining to breast cancer, and interviewed them within 6 month after the cases were recruited. We recruited our controls with a broad spectrum of diagnoses from the Department of Medicine or Surgery from the same hospital of the cases came from. We excluded cases and controls with prior history of physician-diagnosed cancer in any site. This study was approved by the Joint Chinese University of Hong Kong-New Territories East Cluster Clinical Research Ethics Committees and the Kowloon West Cluster, and was strictly compliance with local law and the Declaration of Helsinki.

A standardized questionnaire gathered information on socio-demographic characteristics, tobacco smoking, alcohol drinking, dietary habits such as tea and coffee consumption patterns, hormone-related factors including menopausal status, anthropometric risk factors, history of chronic diseases including breast diseases, family cancer history, physical activity, and occupational history including shift work.

We asked each participant to report their coffee consumption patterns. Participants who drank any type of coffee product at least once a week over 5 years prior to our recruitment time frame were identified as habitual coffee drinkers, whereas those who did not have such a habit were defined as non-habitual coffee drinkers. We further requested the habitual coffee drinkers to provide information on the coffee product that they consumed (instant coffee, brewed coffee, etc.), number of cups (defined as $250 \mathrm{ml}$ per time) and years of coffee consumption. The category of 'instant coffee' refers to the coffee that is soluble and ready to drink. For instance, three-in-one instant coffee is the mixture of soluble coffee, non-dairy creamer and sugar. Brewed coffee refers to the coffee that requires different brewing processes before consumption, such as being boiled and filtered. For the participants who have switched their habitual consumption type of coffee (i.e. from an instant coffee drinker to a brewed coffee drinker, or vice versa), the recent type of coffee comsumption were defined as their habitual consumption types; if the participants' habits of recent type of coffee comsuption were less than 5 years, they were then defined as the previous type coffee drinkers.

Statistical analysis. Independent t-tests and chi-square test were performed to compare the differences between cases and controls for the continuous and categorical variables, respectively. We estimated the adjusted odds ratios (AOR) and 95\% confidence interval (95\% CI) for the associations between different coffee products and breast cancer with an unconditional multivariate logistic regression model. The reference group was defined as the participants who did not have a habitual coffee consumption (i.e., coffee drinking vs. non-coffee drinking; instant coffee drinking vs. non- coffee drinking). We adjusted for potential confounders including the participant's age, educational attainment, family breast cancer history, previous history of benign breast diseases, menopausal status, body mass index (BMI), shift work, smoking habits, alcohol and tea drinking consumption, and deep fried food and green vegetable consumption. Further stratified analyses were conducted according to their menopausal status. Postmenopausal status was determined if the participants reported their menstrual periods stopped more than a year; otherwise, pre-menupausal status was defined. All statistical analyses were conducted with SPSS 20.0 for Windows (SPSS, Chicago, IL, USA), and two-sided p-value less than 0.05 was considered statistically significant. 


\section{Data Availability}

The results and materials described in the article, and the relevant raw data related to coffee drinking can be freely available upon the request to the corresponding author.

\section{References}

1. WHO. Breast cancer, http://www.who.int/cancer/prevention/diagnosis-screening/breast-cancer/en/ (2018).

2. Statista. Coffee, https://www.statista.com/outlook/30010000/118/coffee/hong-kong (2018).

3. Loomis, D. et al. Carcinogenicity of drinking coffee, mate, and very hot beverages. Lancet Oncol 17, 877-878, https://doi. org/10.1016/S1470-2045(16)30239-X (2016).

4. Ganmaa, D. et al. Coffee, tea, caffeine and risk of breast cancer: a 22-year follow-up. Int J Cancer 122, 2071-2076, https://doi. org/10.1002/ijc.23336 (2008).

5. Jiang, W., Wu, Y. \& Jiang, X. Coffee and caffeine intake and breast cancer risk: an updated dose-response meta-analysis of 37 published studies. Gynecol Oncol 129, 620-629, https://doi.org/10.1016/j.ygyno.2013.03.014 (2013).

6. Lowcock, E. C., Cotterchio, M., Anderson, L. N., Boucher, B. A. \& El-Sohemy, A. High coffee intake, but not caffeine, is associated with reduced estrogen receptor negative and postmenopausal breast cancer risk with no effect modification by CYP1A2 genotype. Nutr Cancer 65, 398-409, https://doi.org/10.1080/01635581.2013.768348 (2013).

7. Nilsson, L. M., Johansson, I., Lenner, P., Lindahl, B. \& Van Guelpen, B. Consumption of filtered and boiled coffee and the risk of incident cancer: a prospective cohort study. Cancer Causes Control 21, 1533-1544, https://doi.org/10.1007/s10552-010-9582-X (2010).

8. Fagherazzi, G., Touillaud, M. S., Boutron-Ruault, M. C., Clavel-Chapelon, F. \& Romieu, I. No association between coffee, tea or caffeine consumption and breast cancer risk in a prospective cohort study. Public Health Nutr 14, 1315-1320, https://doi. org/10.1017/S1368980011000371 (2011).

9. Hashibe, M. et al. Coffee, tea, caffeine intake, and the risk of cancer in the PLCO cohort. Br J Cancer 113, 809-816, https://doi. org/10.1038/bjc.2015.276(2015).

10. Lafranconi, A. et al. Coffee Intake Decreases Risk of Postmenopausal Breast Cancer: A Dose-Response Meta-Analysis on Prospective Cohort Studies. Nutrients 10, https://doi.org/10.3390/nu10020112 (2018).

11. Ferrini, R. L. \& Barrett-Connor, E. Caffeine intake and endogenous sex steroid levels in postmenopausal women. The Rancho Bernardo Study. Am J Epidemiol 144, 642-644 (1996).

12. Fish, I. 30\% of instant coffee samples failed biotoxicity test and some contain $90 \%$ additives Vitargent publishes safe to buy list of instant coffee rated "Green Fish", https://www.fishqc.com/en/information-72 (2017).

13. Lee, W. J. \& Zhu, B. T. Inhibition of DNA methylation by caffeic acid and chlorogenic acid, two common catechol-containing coffee polyphenols. Carcinogenesis 27, 269-277, https://doi.org/10.1093/carcin/bgi206 (2006).

14. Kotsopoulos, J., Eliassen, A. H., Missmer, S. A., Hankinson, S. E. \& Tworoger, S. S. Relationship between caffeine intake and plasma sex hormone concentrations in premenopausal and postmenopausal women. Cancer 115, 2765-2774, https://doi.org/10.1002/ cncr.24328 (2009).

15. Fuhrman, B. J. et al. Estrogen metabolism and risk of breast cancer in postmenopausal women. J Natl Cancer Inst 104, 326-339, https://doi.org/10.1093/jnci/djr531 (2012).

16. Simpson, E. R. Sources of estrogen and their importance. J Steroid Biochem Mol Biol 86, 225-230 (2003).

17. Key, T. et al. Endogenous sex hormones and breast cancer in postmenopausal women: reanalysis of nine prospective studies. J Natl Cancer Inst 94, 606-616 (2002).

18. Gross, G., Jaccaud, E. \& Huggett, A. C. Analysis of the content of the diterpenes cafestol and kahweol in coffee brews. Food Chem Toxicol 35, 547-554 (1997).

19. Cavin, C. et al. Cafestol and kahweol, two coffee specific diterpenes with anticarcinogenic activity. Food Chem Toxicol 40, 1155-1163 (2002).

20. Cardenas, C., Quesada, A. R. \& Medina, M. A. Insights on the antitumor effects of kahweol on human breast cancer: decreased survival and increased production of reactive oxygen species and cytotoxicity. Biochem Biophys Res Commun 447, 452-458, https:// doi.org/10.1016/j.bbrc.2014.04.026 (2014).

21. Wang, J., John, E. M., Horn-Ross, P. L. \& Ingles, S. A. Dietary fat, cooking fat, and breast cancer risk in a multiethnic population. Nutr Cancer 60, 492-504, https://doi.org/10.1080/01635580801956485 (2008).

22. Kim, H. J., Cho, S., Jacobs, D. R. Jr. \& Park, K. Instant coffee consumption may be associated with higher risk of metabolic syndrome in Korean adults. Diabetes Res Clin Pract 106, 145-153, https://doi.org/10.1016/j.diabres.2014.07.007 (2014).

23. Furberg, A. S. et al. Metabolic and hormonal profiles: HDL cholesterol as a plausible biomarker of breast cancer risk. The Norwegian EBBA Study. Cancer epidemiology, biomarkers \& prevention: a publication of the American Association for Cancer Research, cosponsored by the American Society of Preventive Oncology 14, 33-40 (2005).

24. Hong Kong Cancer Registry Hospital Authority. Cancer Statistics Query Systems, http://www3.ha.org.hk/cancereg/allages.asp (2018).

25. Li, L., Zhang, M. \& Holman, D. Population versus hospital controls for case-control studies on cancers in Chinese hospitals. BMC medical research methodology 11, 167, https://doi.org/10.1186/1471-2288-11-167 (2011).

26. Li, M. et al. Nighttime eating and breast cancer among Chinese women in Hong Kong. Breast Cancer Res 19, 31, https://doi. org/10.1186/s13058-017-0821-x (2017).

\section{Acknowledgements}

The authors would like to thank Research Grants Council of Hong Kong (Grant number 474811) for the support, and grateful to Miss Yin-Shan Magdalene LEUNG, Hung-Kuen Ivy HSU, Kit-Ping Apple KWOK, Tess Hiu Man TSOI for their assistance in patients' recruitment and data collection. Special Thanks to Prof. Xiaohong Rose YANG from National Institutes of Health for her guidance and support. The authors also thank the patients and staff of the departments of oncology and surgery for their supports. The work was supported by the Research Grants Council of Hong Kong (Grant number 474811).

\section{Author Contributions}

L.A.T. designed and oversaw the conduct of this present study. P.M.Y.L. reviewed the literature, analyzed the data and drafted the manuscript under the supervision of L.A.T. W.F. contributed to the questionnaire design and liaison with the studied hospitals. W.C.C. coordinate the data collection and contribute ideas in study design and revision. C.H.K., W.C.Y., Y.C.Y. organized and managed the field work at Princess Margaret Hospital. W.C.C. and C.W. organized and managed the field work at North District Hospital. S.H.L. and K.H.T. organized and managed the field work at Yan Chai Hospital. C.K.M.W. and L.D.J.C. contributed to suggest some ideas and improve the 
English writing of this manuscript. All authors contributed to the development of this manuscript and approved the final version of this manuscript.

\section{Additional Information}

Supplementary information accompanies this paper at https://doi.org/10.1038/s41598-019-49205-x.

Competing Interests: The authors declare no competing interests.

Publisher's note: Springer Nature remains neutral with regard to jurisdictional claims in published maps and institutional affiliations.

(c) (i) Open Access This article is licensed under a Creative Commons Attribution 4.0 International License, which permits use, sharing, adaptation, distribution and reproduction in any medium or format, as long as you give appropriate credit to the original author(s) and the source, provide a link to the Creative Commons license, and indicate if changes were made. The images or other third party material in this article are included in the article's Creative Commons license, unless indicated otherwise in a credit line to the material. If material is not included in the article's Creative Commons license and your intended use is not permitted by statutory regulation or exceeds the permitted use, you will need to obtain permission directly from the copyright holder. To view a copy of this license, visit http://creativecommons.org/licenses/by/4.0/.

(C) The Author(s) 2019 